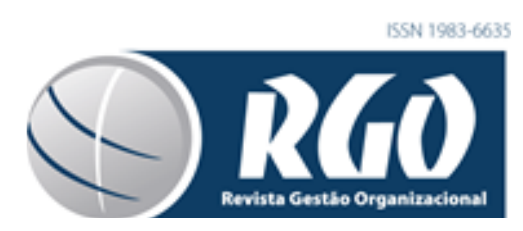

\title{
FUNÇÕES DAS CONTROLADORIAS MUNICIPAIS: UM ESTUDO NAS PREFEITURAS DAS CAPITAIS BRASILEIRAS
}

\author{
FUNCTIONS OF MUNICIPAL CONTROLLERS: \\ A STUDY IN THE CITY HALLS OF BRAZILIAN CAPITALS
}

\author{
TÁCIO MARQUES DA CUNHA \\ Mestrando em Controladoria \\ Programa de Pós-Graduação em Controladoria - Universidade Federal Rural de Pernambuco \\ Orcid: http://orcid.org/0000-0002-8310-562X \\ E-mail: taciomarquesac@gmail.com \\ Endereço: Rua Soldado Joaquim Xavier, 151, Tejipió, Recife - PE.
}

\begin{abstract}
ALDO LEONARDO CUNHA CALLADO
Doutor em Agronegócios

Professor no PPG em Administração e PPG em Ciências Contábeis - Universidade Federal da Paraíba Professor no PPG em Controladoria - Universidade Federal Rural de Pernambuco

Orcid: http://orcid.org/0000-0002-5393-6094

E-mail: aldocallado@yahoo.com.br
\end{abstract}

\begin{abstract}
RESUMO
O estudo objetivou identificar como se caracterizam as controladorias das prefeituras das capitais do Brasil, sobretudo no que se refere às funções executadas por estes órgãos. A metodologia se caracterizou como exploratória e descritiva, com abordagem quantitativa. Quanto aos procedimentos técnicos utilizados, configurou-se como uma pesquisa de levantamento (survey) por intermédio da aplicação de questionário específico aplicado aos responsáveis pela Unidade Central de Controle Interno (UCCI) das prefeituras das capitais brasileiras. Os achados, no tocante às características das unidades, permitiram concluir que elas são denominadas Controladoria Geral do Município, formalizadas como secretarias, as quais funcionam 8 horas por dia e tem dotação orçamentária acima de $\mathrm{R} \$ 1.000 .000,00$, que em grande parte são compostas por mais de 25 profissionais que não são da carreira de controle. Quanto à identificação das funções desempenhadas pelas Controladorias Públicas Municipais, percebeu-se que a função controle interno foi a única executada por todas as unidades participantes do estudo, enquanto que a função gerencial estratégica foi exercida por $73,3 \%$, seguida pela função proteção e controle de ativos (60\%), e controle de risco (53,3\%). As funções contábil e tributária aparecem com igual representatividade, sendo desempenhada por 6 das 15 unidades. Os dados também demonstraram que 80\%, representando 12 unidades participantes, executam de 03 a 05 funções da controladoria.
\end{abstract}

Palavras-chave: Controladoria municipal. Funções da controladoria. Prefeituras brasileiras.

Data de submissão: 05/11/2019. Data de aceite: 08/12/2019. Data de publicação: 17/12/2019.

Artigo selecionado no fast track do COGECONT - International Conference in Management and Accounting, realizado na Universidade Comunitária da Região de Chapecó - Unochapecó, Chapecó - SC, de 17 a 19/10/2019. 


\begin{abstract}
The study aimed to identify how the controllers of the prefectures of the capitals of Brazil are characterized, especially with regard to the functions performed by these organs. The methodology was characterized as exploratory and descriptive, with quantitative approach. As for the technical procedures used, it was configured as a survey through the application of a specific questionnaire applied to those responsible for the Central Internal Control Unit (UCCI) of the Brazilian capital city halls. The findings, regarding the characteristics of the units, led to the conclusion that they are called the Comptroller General of the Municipality, formalized as secretariats, which work 8 hours a day and have a budget of over $\mathrm{R} \$$ $1,000,000.00$, which in large part They are made up of over 25 non-career professionals. Regarding the identification of the functions performed by the Municipal Public Controllers, it was noticed that the internal control function was the only one performed by all units participating in the study, while the strategic managerial function was performed by $73.3 \%$, followed by the protection and asset control (60\%), and risk control (53.3\%). The accounting and tax functions appear with equal representation, being performed by 6 of the 15 units. The data also showed that $80 \%$, representing 12 participating units, perform from 03 to 05 controllership functions.
\end{abstract}

Keywords: Municipal controller. Controllership functions. Brazilian City halls.

\title{
1 INTRODUÇÃO
}

Nos últimos anos, o Brasil tem vivenciado constantes escândalos de corrupção envolvendo a gestão de recursos públicos, comprometendo a credibilidade da administração das instituições públicas brasileiras, o que inclui as atividades exercidas pelas prefeituras municipais. Neste cenário, as ações de controle sobre as operações contábeis, orçamentárias, financeiras, operacionais e patrimoniais têm sido adotadas como meio de permitir, aos gestores destas entidades, uma melhor gestão do patrimônio público (OLIVEIRA JÚNIOR; CHAVES JÚNIOR; LIMA, 2009).

Os mesmos autores ainda destacam que estas ações podem avaliar a exatidão e regularidade das contas públicas, e ainda mensurar a economicidade, a eficiência e a legalidade da gestão governamental, devendo estar harmoniosamente consolidadas em um único órgão administrativo, ou unidade organizacional. Segundo Cruz, Silva e Spinelli (2016), no âmbito dos municípios, a preocupação com o controle do governo e das políticas públicas, é responsabilidade do órgão central comumente denominado de Controladoria Geral do Município (CGM).

De acordo com Azevedo e Leitão (2018), a Controladoria pública provém os administradores públicos com informações sobre a eficiência da gestão, cuja suas atividades devem refletir nas diversas funções que abranjam o controle gerencial, incluindo o controle interno das entidades públicas. Almeida, Taffarel e Gerigk (2003) corroboram com o entendimento anterior quando introduzem que a Controladoria tem como objetivo principal permitir aos governantes municipais 0 acesso às informações sobre o efetivo desenvolvimento de suas propostas de governo, a partir do posicionamento sobre o cumprimento das metas pré-estabelecidas sem a interferência de sua execução.

Soares (2012) complementa que o Sistema de Controle Interno confere, além do acompanhamento do exercício das atividades orçamentária, financeira, contábil, patrimonial e operacional, o suporte e orientação pertencentes à legalidade, eficiência e moralidade das 
práticas adotadas, permitindo o atendimento aos interesses da sociedade. Assis, Silva e Catapan (2016) destacam que a controladoria é relevante para os órgãos públicos, pois alinha o fluxo de informações com a finalidade de se atingir os objetivos propostos. Os mesmos autores também mencionam a transparência e accountability como componentes de sustentação da governança alicerçados pela controladoria.

Contudo, embora sejam introduzidos os seus benefícios e exista a exigência legal da Constituição Federal de 1988 quanto à obrigatoriedade da instituição de sistemas de controle interno nas três esferas de governo, nota-se, conforme Azevedo e Leitão (2018) e Cruz et al. (2014), que em muitos municípios não se desenvolveram unidades de controle interno, e outras estão em fase de implementação. É importante ressaltar também que os órgãos públicos brasileiros não apresentam as funções da controladoria de maneira consolidada, como outros países, a exemplos da Alemanha e dos Estados Unidos (LUNKES; SCHNORRENBERGER; ROSA, 2013).

Diante destas limitações surge a questão-problema deste estudo, que consiste em responder: quais as funções executadas pelas controladorias das prefeituras das capitais brasileiras? Nesse sentido, o objetivo desta pesquisa é identificar as funções de controladoria exercidas pelas controladorias nas prefeituras das capitais do Brasil.

$O$ referido estudo se justifica por identificar como se caracterizam as controladorias das prefeituras das capitais do país, sobretudo no que se refere às funções executadas. Também é possível confrontar as funções de controladoria mais citadas na literatura com aquelas efetivamente exercidas pelas controladorias municipais.

\section{REVISÃO DA LITERATURA}

Nesta seção teórica, serão abordadas temáticas relacionadas ao estudo. A primeira subseção trata sobre aspectos gerais da controladoria, seguido pelas considerações sobre as funções da controladoria, na sequência a abordagem da mesma na realidade da esfera pública municipal.

\subsection{CONTROLADORIA: ASPECTOS GERAIS}

A controladoria ascende como uma área de estudo consequente das demandas do mercado competitivo, no qual estão inseridas às organizações. No cenário global, a controladoria surge em meados do século XIX, primeiramente na esfera pública para despontar posteriormente na esfera privada, nas empresas ferroviárias norte-americanas devido às exigências da área financeira (CHANDLER, 1962). Conforme Souza (2015), a emergência da controladoria no cenário brasileiro ocorre no início do século XX, e é explicada pela entrada e expansão das empresas multinacionais, devido à abertura econômica ao capital estrangeiro e a industrialização no governo de Juscelino Kubitschek (1956-1961).

De origem recente, muitos aspectos de sua natureza ainda não estão claramente estabelecidos, o que também pode ser explicado pelo seu surgimento está relacionado à evolução da prática contábil tradicional (MELLER; LOPES; LUNKES, 2014). Esta carência de bases sólidas estende-se às suas definições, o que culmina em diferentes concepções conceituais (VASCONCELOS; LIMA, 2017). Contudo, grande parte dos autores que tratam sobre a controladoria em seus estudos, explanam suas definições por meio de duas grandes vertentes: como departamento da organização e como área do conhecimento humano.

Como uma área do conhecimento humano, a controladoria caracteriza-se como um conjunto de saberes decorrentes de fundamentos, princípios, métodos e contribuições de 
outras ciências como a administração, economia, psicologia, estatística, contabilidade, matemática, direito e sociologia (CALIJURI; SANTOS; SANTOS, 2005; BORINELLI, 2006). De acordo com Borinelli (2006), a controladoria constitui-se de bases teóricas e conceituais que auxiliam a gestão organizacional do ponto de vista operacional, contábil, financeiro, econômico e patrimonial.

Como departamento da organização, a controladoria é definida como a unidade administrativa de uma corporação constituída de missão, objetivos e funções próprias. Responsabilizada pelo alcance dos propósitos organizacionais, a controladoria é compreendida como ferramenta de auxílio à tomada de decisão, devido ao seu papel de suporte informacional aos usuários internos sobre eventos, transações e atividades econômicas da entidade (BORINELLI, 2006; PELEIAS, 2002; MONTEIRO; BARBOSA, 2011). Oliveira, Perez Jr. e Silva (2011, p. 5) corroboram o entendimento exposto salientando a área de controle interno como um "departamento responsável pelo projeto, elaboração, implementação e manutenção do sistema integrado de informações operacionais, financeiras e contábeis".

Sobre a repartição da instituição, Prestes e Assunção (2015) asseguram que ela tem como missão assessorar a administração e zelar pela continuidade de suas atividades. Gonçalves (2013) define que sua missão envolve a integração de todos os setores permitindo a implantação de sistemas que viabilizem o alcance dos resultados. Quanto aos seus objetivos, enquanto unidade organizacional, Borinelli (2006) aponta o subsídio ao processo de gestão em todas as etapas, monitoramento e garantia de informações úteis para tomada de decisão, além do desenvolvimento das relações com os stakeholders que se relacionam com a empresa.

No que concerne ao profissional da controladoria, o controller, têm sua aparição no cenário brasileiro reconhecida por volta de 1962, alcançando maior representatividade nos anos 1980, devido ao crescimento e aumento da complexidade das empresas, e da instalação de organizações estrangeiras e multinacionais, forçando as empresas nacionais a se reestruturarem, o que incluiu a prática da controladoria (SIQUEIRA; SOLTELINHO, 2001).

Os profissionais da controladoria também têm sua atuação caracterizada por diversas concepções no cenário organizacional, o que pode ser observado pelas variâncias ocorrentes quando se analisa o seu papel em distintas empresas. Corroborando com o exposto, Oliveira (2015) afirma que o controller adapta suas ações laborais à cultura da entidade, podendo, segundo Schmidt e Santos (2014), desempenhar seu trabalho com diferentes atribuições.

O estudo realizado por Cunha, Amorim e Silva (2018), a partir de um vasto levantamento bibliográfico realizado com literaturas nacionais e internacionais, identificou que o controller deve possuir um considerável número de competências, o que comunica a multiplicidade de conhecimentos, habilidades e atitudes atribuídos ao profissional, confirmando a abrangência de sua atuação, que compreende desde competências básicas para o exercício da profissão contábil, até experiências e práticas de gestão organizacional, o que envolve o auxílio à tomada de decisão, o planejamento estratégico e a gestão de pessoas.

Isto denota o motivo pelo qual a formação acadêmica dos mesmos, no cenário acadêmico atual, ocorre massivamente nas áreas de Ciências Contábeis e Administração e Economia, como afirmam Borinelli (2006) e Beuren, Bogoni e Fernandes (2008). Contudo, Oro et al. (2009) evidenciam que engenheiros e analistas de sistemas também têm ocupado o cargo de controller.

Quanto às funções da controladoria nota-se, na literatura e nas práticas organizacionais, diferentes perspectivas, entrave justificado pelo seu nascimento ser 
principiante na prática, seguido de sua abordagem no meio acadêmico (MELLER; LOPES; LUNKES, 2014). Por esta razão, serão apresentadas na seção a seguir, as diversas concepções verificadas na literatura quanto às funções que a controladoria deve exercer.

\subsection{FUNÇÕES DA CONTROLADORIA}

Devido ao seu surgimento da prática contábil, a controladoria não possui uma padronização quanto às suas funções (MELLER; LOPES; LUNKES, 2014). Certificando a afirmação exposta, Sartoratto, Lunkes e Rosa (2016) salientam que a controladoria está em processo de consolidação de suas funções, o que implica nas diferentes concepções quanto às suas atividades, devido às influências modelo de gestão e de cada estrutura organizacional.

Um levantamento das funções da controladoria, sob a ótica de diferentes autores, ao longo do tempo, é apresentado no Quadro 1.

Quadro 1 - Funções da Controladoria

\begin{tabular}{|c|c|}
\hline AUTORES & FUNÇÕES DA CONTROLADORIA \\
\hline Kanitz (1976) & $\begin{array}{l}\text { Direção e a implantação dos sistemas organizacionais de informação, motivação, } \\
\text { coordenação, avaliação, planejamento e acompanhamento. }\end{array}$ \\
\hline $\begin{array}{l}\text { Willson, Roehl- } \\
\text { Anderson e Bragg } \\
\text { (1995) }\end{array}$ & Função de planejamento, informativa, controle e contábil. \\
\hline Peleias (2002) & $\begin{array}{l}\text { Empreender esforços para suprir os gestores com ferramentas de informática que } \\
\text { permitam o planejamento, o registro e o controle das decisões tomadas em cada fase } \\
\text { do processo de gestão. }\end{array}$ \\
\hline Borinelli (2006) & $\begin{array}{l}\text { Funções contábil, gerencial, custos, tributária, controle interno, riscos e gestão da } \\
\text { informação. }\end{array}$ \\
\hline $\begin{array}{l}\text { Beuren, Bogoni e } \\
\text { Fernandes (2008) }\end{array}$ & $\begin{array}{l}\text { Gestão de informações, contábil, gerencial, custos, controles internos e tributação, } \\
\text { proteção e controle de ativos }\end{array}$ \\
\hline $\begin{array}{l}\text { Nascimento e } \\
\text { Reginato (2010) }\end{array}$ & $\begin{array}{l}\text { Promover a integração entre as áreas, através do suprimento de informações, utilizar } \\
\text { os sistemas de informação, que devem considerar os preceitos dos modelos de decisão, } \\
\text { mensuração e informação da empresa, subsidiar os gestores com informações que lhes } \\
\text { conduzem à melhor escolha entre diversas alternativas possíveis. }\end{array}$ \\
\hline $\begin{array}{l}\text { Suzart, Marcelino e } \\
\text { Rocha (2011) }\end{array}$ & $\begin{array}{l}\text { Função contábil, gerencial-estratégica, tributária, proteção e controle dos ativos, } \\
\text { controle interno e controle de riscos. }\end{array}$ \\
\hline $\begin{array}{l}\text { Lunkes, } \\
\text { Schnorrenberguer e } \\
\text { Rosa (2013) }\end{array}$ & $\begin{array}{l}\text { Função contábil, controle, administração de impostos, planejamento, elaboração de } \\
\text { relatórios e interpretação, controle interno, sistemas de informações, auditoria, custos, } \\
\text { orçamento, planejamento. }\end{array}$ \\
\hline CGMA (2014) & $\begin{array}{l}\text { Custo de transformação e gestão, relatórios externos, estratégia financeira, controle } \\
\text { interno, avaliação de investimentos, controle e gestão orçamentária, decisão sobre } \\
\text { preço, desconto e produto, gestão de projetos, aderência e conformidade à } \\
\text { regulamentação, gestão de recursos, gestão de risco, gestão tributária estratégica, } \\
\text { tesouraria e gestão de caixa, auditoria interna. }\end{array}$ \\
\hline
\end{tabular}

Fonte: Elaborado pelos autores.

Diante do levantamento dos autores que discorrem sobre as funções da controladoria, percebe-se que tais atribuições compreendem desde atividades básicas da contabilidade até as práticas de gestão estratégica, a saber: função contábil e gerencial; custos; gestão de tributos, impostos e riscos; controles internos; gestão da informação; proteção e controle de ativos; subsídio ao processo de gestão; apoio à avaliação de desempenho; promoção da integração entre as áreas organizacionais; auditoria e orçamento; e motivação, coordenação, avaliação, planejamento e acompanhamento de todos os setores. 
Este misto de funções básicas e estratégicas da contabilidade é definido por Weber (2011) através das funções do controller conforme dois grandes grupos: o "contador de feijão" e o "parceiro de negócios". As funções do "contador de feijão" estão relacionadas a um perfil tecnicista do controller que envolvem atividades básicas da contabilidade, já as funções do "parceiro de negócios" envolvem atividades de planejamento e controle estratégico, bem como o apoio na tomada de decisão.

No âmbito da esfera pública municipal, embora não exista distinção, na literatura, das atividades da controladoria que devem ser exercidas nas esferas privadas, Almeida, Taffarel e Gerigk (2003) elencaram como funções: implantação de nova sistemática de controle interno; auxílio na definição de metas da Administração Municipal; controlar e cobrar os resultados obtidos, bem como corrigir os desvios; controlar as receitas e despesas; prover o Prefeito, seus Secretários e os Gestores da Administração Indireta com informações úteis; participar da discussão e elaboração do Plano Plurianual-PPA, da Lei de Diretrizes Orçamentárias-LDO e da Lei Orçamentária Anual-LOA; viabilizar às informações ao Legislativo Municipal e à população; dentre outras.

A abordagem da controladoria na realidade das prefeituras municipais, ainda é um tema pouco explorado, visto que através do levantamento realizado, encontraram-se algumas pesquisas aplicadas a realidade dos municípios, são elas: Rebién e Amorim (2008), Cavalcante, Peter e Machado (2011), Eckert et al. (2012), Cruz et al. (2014), Rodrigues e Betim (2014) e Silva, Carneiro e Ramos (2015), Silveira, Gasparetto, Lunkes e Schnorrenberger (2018), Azevedo e Leitão (2018), Bonetti, Wernke e Zanin (2018).

Nestes dois últimos, realizou-se, também, uma investigação das funções executadas pelas controladorias das prefeituras municipais. Conforme Azevedo e Leitão (2018), na realidade dos municípios pernambucanos, as funções controle interno, contábil, gerencial e controle de riscos foram as mais exercidas, enquanto que as funções proteção e controle de ativos e tributários apareceram foram menos expressivas.

Os achados de Bonetti, Wernke e Zanin (2018) apontaram que no universo das prefeituras municipais do sudoeste do Paraná, as funções da controladoria são executadas em consonância com as definidas pela literatura, atuando com maior incidência nas funções gerencial-estratégica, proteção de ativos, avaliar orçamento, controle de riscos e, em menor, nas funções custos, contábil, planejamento/controle e tributária.

O estudo de Silveira, Gasparetto, Lunkes e Schnorrenberger (2018), identificou através da análise das vagas de controlador ofertadas em concursos públicos em 60 editais brasileiros, que as funções mais citadas foram controle, controle interno, auditoria, e avaliação e consultoria. Silveira, Gasparetto, Lunkes e Schnorrenberger $(2018$, p. 133) ainda ponderam que a controladoria "funciona como setor de observação e controle da administração e de que é por meio dela que dados e informações serão minuciosamente detalhados com o intuito de detectar possíveis falhas no processo".

Nota-se que a abordagem das funções da controladoria também não é consensual na esfera pública, assim como acontece na literatura, embora demonstrem pontos congruentes, como a execução das funções controle de ativos e gerencial com maior representatividade, e das funções controle e tributárias com menor execução. Percebe-se, também, que o perfil exigido ao profissional da controladoria, em decorrência das funções elencadas, demonstra um misto de funções tecnicistas e gerenciais-estratégicas, o que comunica uma mudança na realidade do mesmo assim como vem ocorrendo na iniciativa privada. 


\subsection{CONTROLADORIA MUNICIPAL}

A controladoria como setor ou área do conhecimento humano, tem demonstrado sua relevância no que tange ao fornecimento de informações gerenciais que apoiam seus gestores no processo decisório. Benĉová e Kal'avská (2009) confirmam que as informações por ela produzidas são responsáveis pelo alcance dos objetivos organizacionais, justificando que por seu intermédio é possível adaptar a entidade às exigências do ambiente que ela integra.

Quando se trata das instituições na esfera pública, existe uma ínfima confusão no tocante aos significados da controladoria e do controle, mas que pode ser explicada devido à relação tênue existente entre eles. Conforme Borinelli (2006), a controladoria é uma área de natureza ampla, que abarca todos os procedimentos relacionados ao protecionismo patrimonial e ao controle de gestão, estando o controle associado à sua prática, bem como o controle interno representado como uma de suas funções.

Para consecução de seus objetivos, Nascimento e Reginato (2010) elucidam que a controladoria necessita de uma estrutura adequada de controles internos sustentados por um apropriado sistema de controle. Neste âmbito, Souza e Dorigon (2012) defendem que a materialização organizacional da controladoria ocorre por meio do controle interno.

Segundo Bonetti, Wernke e Zanin (2018), outra confusão conceitual que se faz ocorre na relação entre a controladoria e auditoria, pois, segundo os autores, ao tratar sobre a controladoria na esfera pública, tem-se o entendimento de aplicação de ações e normas de controle. Os mesmos autores ainda salientam que nem sempre os gestores têm domínio do conceito e aplicabilidade da controladoria em órgão público, daí surge a necessidade de o administrador público conhecer bem o órgão que dirige no que se refere à sua estrutura, necessidades, previsões, orçamentos e planejamentos.

Um fator que possibilita estas confusões e a própria falta de conhecimento dos gestores públicos sobre a controladoria são os dispositivos legais, já que em seus textos não existem imposições sobre a controladoria, mas sim sobre o controle interno, são eles: a Lei 4.320 de 1964; a Constituição Federal de 1988; e a Lei Complementar 101 de 2000, comumente denominada Lei de Responsabilidade Fiscal (LRF). Todos abordam sobre a obrigatoriedade e execução do controle interno, reforçando à sua existência nas instituições públicas.

De acordo com Carneiro Júnior e Oliveira (2012), estas imposições legais têm exigido dos controles internos uma maior responsabilidade das entidades públicas com os gastos para não ocasionar um cenário de déficit público, ou ainda cortes de benefícios e verbas oriundos de ingerência dos recursos públicos. Cruz e Glock (2003, p. 19) destacam que o controle interno na área pública representa um compromisso com "a garantia de que os aspectos legais estão sendo rigorosamente observados".

Soares (2012) vai além da importância dos controles internos pela obrigatoriedade legal, quando afirma que fiscalizar e orientar a administração pública representa uma necessidade que deve levar em conta o objetivo maior da gestão, o bem social. Estas percepções são corroboradas por Vasconcelos, Sampaio, Silva Neto e Duque (2012), ao defender que a controladoria governamental é um instrumento relevante para auxiliar à gestão pública municipal, visto que sua finalidade é impulsionar o município a atingir a eficiência, eficácia e economicidade prezando pela transparência dos atos praticados pelo gestor público.

Roza, Alberton e Lunkes (2009) argumentam, portanto, que este cenário pode ser alcançado pelas organizações públicas, caso seja dada autonomia e isenção aos Controles Internos quando constatadas não conformidades que diminuem os resultados dos serviços 
públicos. Os autores complementam que, ao tratar da autonomia do controle interno, é necessário compreender que a sua posição hierárquica, dentro da estrutura organizacional da prefeitura, deve ser observada, já que as atividades realizadas por linha têm atuações descentralizadas e participam de maneira ativa nas decisões, e as de staff atuam como órgãos de assessoramento ligados ao executivo municipal.

O Controle Interno Municipal, conforme Chiarelli e Cherobim (2009) é considerado um recurso organizacional importante para sustentabilidade da gestão pública municipal. Este entendimento permite afirmar que, independente da forma como se estrutura hierarquicamente, ou como se é denominada, a Controladoria ou a Unidade Central de Controle Interno de uma prefeitura tem crucial importância para o sucesso da gestão. Embora este entendimento seja compartilhado observa-se, na prática, que em muitas prefeituras não se desenvolvem unidades de controle interno, ou ainda que estas estejam em fase de implementação (AZEVEDO; LEITÃO, 2018; CRUZ et al., 2014).

Diante disto, é importante destacar a necessidade da implantação de um órgão de Controladoria, ou Unidade Central de Controle Interno, nas prefeituras municipais. Esta parte integrante da estrutura organizacional deve ser detentora de ferramentas de controle préestabelecidas, bem como do arranjo de responsabilidades, rotinas de trabalho e mecanismos de revisão, aprovação e registro dos trabalhos, abarcando desde os aspectos contábeis e administrativos, aos ambientais e culturais (CRUZ; GLOCK, 2003).

\section{PROCEDIMENTOS METOdOLÓGICOS}

Em conformidade com os objetivos da pesquisa, o estudo, quanto à sua natureza, caracteriza-se como descritivo e exploratório. A pesquisa descritiva consiste em descrever a as características de determinada população ou fenômeno ou, ainda o estabelecimento de relações entre variáveis (SILVA, 2017). E a pesquisa exploratória, segundo o mesmo autor, ocorre em uma área de pouco conhecimento acumulado, a fim de proporcionar maior proximidade com o problema.

Com relação à abordagem do problema, a pesquisa é do tipo quantitativo dado a tradução dos dados, de opiniões, de informações em números, utilizando-se de recursos e técnicas de estatística (CRESWELL, 2010). Neste estudo foi adotada a estatística descritiva para identificar as funções e características das Controladorias das prefeituras das capitais do Brasil.

Quanto aos procedimentos técnicos utilizados, trata-se de uma pesquisa de levantamento (survey), que segundo Babbie (1999), tem como intuito identificar a distribuição de certos traços e atributos da população estudada mediante a utilização de um instrumento de pesquisa, geralmente o questionário. Gil (2010) aponta o conhecimento direto da realidade, a economia, rapidez, e a quantificação como vantagens do levantamento.

O estudo é considerado de levantamento, pois teve como objetivo identificar informações sobre as funções e características das Controladorias das prefeituras das capitais brasileiras por intermédio da aplicação de questionário específico, que foi encaminhado por e-mail no período de janeiro a fevereiro de 2019. Os participantes são responsáveis pela Unidade Central de Controle Interno (UCCI), as quais podem assumir as denominações de Controle Interno ou Controladorias Gerais, nas respectivas prefeituras investigadas. Após contato telefônico, via e-mail e/ou e-SIC (Sistema Eletrônico do Serviço de Informação ao Cidadão), solicitando-Ihes a participação no estudo.

$\mathrm{O}$ instrumento de pesquisa adotado foi adaptado do questionário utilizado por Azevedo e Leitão (2018), dispensando, portanto, a sua validação, já que houve apenas a 
retirada de uma seção do questionário. O mesmo ficou estruturado em quatro seções, a saber: Seção 1 - Identificação do Respondente; Seção II - Características Gerais da Unidade Central de Controle Interno; Seção III - Perfil do Responsável pela Unidade Central de Controle Interno, e Seção IV - As Funções desempenhadas por Controladorias Públicas Municipais.

Para fins de investigação, foram utilizadas, neste estudo, as funções atribuídas às Controladorias Públicas, definidas por Suzart, Marcelino e Rocha (2011), que são as funções contábil, gerencial-estratégica, tributária, proteção e controle dos ativos, controle interno (subfunções auditoria, corregedoria, ouvidoria e transparência) e controle de riscos.

Quanto ao universo investigado, o estudo abrangeu as prefeituras representantes das 27 capitais brasileiras, com exceção de Brasília, que desde 17 de outubro de 1969, criou o Governo do Distrito Federal, substituindo a prefeitura. Embora o questionário tenha sido enviado para as 27 prefeituras, a análise dos resultados foi realizada considerando que 15 retornaram com os questionários da pesquisa totalmente respondidos, o que representou uma taxa de resposta de 55,5\%. Para tabulação dos dados obtidos, foi utilizado o software Microsoft Excel.

\section{ANÁLISE E DISCUSSÃO DOS RESULTADOS}

\subsection{CARACTERÍSTICAS GERAIS DA CONTROLADORIA OU UNIDADE CENTRAL DE CONTROLE INTERNO}

A fim de levantar as características gerais das Controladorias ou UCCls, foram identificados os seguintes atributos: nomenclatura adotada para o órgão; posição ocupada na estrutura organizacional; carga horária de funcionamento do setor; existência da carreira específica de controle; nomenclatura adotada para a carreira específica de controle; quantidade de profissionais lotados na unidade e seus respectivos enquadramentos funcionais; e ainda a existência de rubrica orçamentária na Lei Orçamentária Anual (LOA) e seus respectivos valores.

Conforme os dados obtidos, quanto à nomenclatura adotada para o órgão de Controladoria ou controle interno, observou-se que a maioria (80\%) é denominado de "Controladoria Geral do Município". Contudo, não há uma padronização quanto à nomenclatura das áreas de controle no setor público, já que outras três denominações também foram notadas "Controladoria e Ouvidoria Geral do Município", "Subsecretaria de Controle Interno" e "Assessoria de Controladoria em Finanças".

Estes achados estão consoantes com a literatura, já que autores como Cruz, Silva e Spinelli (2016), afirmam que na realidade dos municípios, a preocupação com o controle do governo e das políticas públicas, é responsabilidade do órgão central comumente denominado de Controladoria Geral do Município (CGM).

Quanto à posição ocupada na estrutura organizacional, observou-se que $46,7 \%$ já se configuram como secretarias municipais, seguida por $20 \%$, representando as unidades vinculadas à secretaria de finanças, conforme Tabela 1.

Também se identificou que $13,3 \%$ são unidades com status de secretaria. Com o mesmo achado, a posição "Outra" foi especificada pelos participantes, os quais afirmaram que as unidades estão vinculadas a Secretaria Municipal de Transparência e Controladoria da prefeitura a qual representa, enquanto o outro afirmou o vínculo com a Secretaria de Transparência e Controle Interno. Entende-se que não há, também, um padrão quanto à posição hierárquica desta unidade na estrutura organizacional municipal, o que também 
influencia na relação destas com outros departamentos, bem como de sua autonomia nas respectivas prefeituras.

Tabela 1 - Posição ocupada na estrutura organizacional

\begin{tabular}{|c|c|c|}
\hline Posição & Frequência & $\%$ \\
\hline Secretaria & 7 & $46,7 \%$ \\
\hline Órgão com status de Secretaria & 2 & $13,3 \%$ \\
\hline Unidade Vinculada ao Gabinete da Prefeitura & 1 & $6,7 \%$ \\
\hline Unidade Vinculada à Secretaria de Finanças & 3 & $20 \%$ \\
\hline Outra & 2 & $13,3 \%$ \\
\hline
\end{tabular}

Fonte: Dados da Pesquisa.

Estas observações estão em conformidade com a concepção de Roza, Alberton e Lunkes (2009) a respeito da relação e autonomia destas unidades em consonância com a posição hierárquica que ocupam, já que os órgãos de assessoramento ligados ao executivo municipal têm suas atuações descentralizadas, sendo unidades de staff. Já os órgãos que possuem atuações descentralizadas, participam ativamente das tomadas de decisões e se configuram como órgãos de linha.

Em relação à carga horária, os resultados obtidos permitem afirmar que $80 \%$ das unidades participantes possuem uma carga horária de funcionamento diária de 8 horas, e enquanto três funcionam 6 horas por dia.

No que se refere a carreira de controle, a maioria $(66,7 \%)$ afirmou possuir ter. De acordo com Azevedo e Leitão (2018), a criação de uma carreira específica para o controle fortalece as atividades de Controladoria na área pública, uma vez que diminui a rotatividade das pessoas que atuam no setor, bem como possibilita autonomia de atuação.

As Controladorias ou UCCls que afirmaram possuir esta carreira municipal atribuíram aos cargos as seguintes denominações "Auditor interno", "Auditor Municipal de Controle Interno", "Auditor Público Interno", "Analista de Controle Interno", "Analista de Planejamento e Gestão" e "Controlador de Recursos Municipais". Da mesma forma que não existe uniformidade quanto à nomenclatura das UCCls, ocorre para a nomenclatura das carreiras de controle.

Observa-se, também, a presença da terminologia "auditoria", o que pode ser explicado pela confusão conceitual entre controladoria e auditoria, explicada por Bonetti, Wernke e Zanin (2018).

Outro atributo importante com relação aos profissionais atuantes nas áreas de controle municipal é a sua quantidade. Conforme dados levantados, a maioria $(53,3 \%)$ das unidades é composta por mais de 25 profissionais. Notou-se, também, que todas as controladorias ou UCCls participantes têm pelo menos 02 profissionais atuando em suas atividades.

Do quantitativo de profissionais lotados, também foi investigado o seu enquadramento funcional, constatando-se que todas as áreas de controle interno possuem servidores que não sejam da carreira de controle, seguidos pelos profissionais que se enquadram como servidores da carreira de controle (93,3\%), e os funcionários comissionados $(86,7 \%)$. Com a mesma expressividade, foram apontas os enquadramentos terceirizados, contratados por tempo determinado e os estagiários (60\%). Os achados destes atributos são semelhantes aos encontrados por Azevedo e Leitão (2018).

Conforme justificam as autoras Azevedo e Leitão (2018), o grande número de comissionados dificulta a continuidade das ações do controle municipal, pois a natureza do cargo é rotativa. Contudo, esta rotatividade pode representar ganhos importantes pela experiência do mercado privado, aplicadas a gestão pública municipal. 
Embora também todas as unidades possuam servidores que não são da carreira de controle municipal, os mesmos são profissionais da gestão pública que podem contribuir com experiência de outros departamentos governamentais, o que também é corroborado por Azevedo e Leitão (2018).

O último, e não menos importante atributo investigado para caracterizar as áreas investigadas refere-se ao orçamento que as mesmas possuem para desenvolver suas ações. Para este fim, questionou-se aos respondentes, se as Controladorias ou UCCls das prefeituras que eles representam possuíam rubrica orçamentária na LOA do exercício de 2019.

As respostas dos participantes revelaram que a maioria possui rubrica orçamentária exclusiva para o controle municipal. No entanto, cinco unidades afirmaram não possuir, e apenas uma não soube informar quanto à sua existência.

Nos casos em que as unidades de controle municipal afirmaram possuir rubrica, 08 informaram os seus valores. Embora tenha se identificado que o valor total da dotação orçamentária anual é bem diferente de uma para outra, a maioria apresentou valores acima de $\mathrm{R} \$ 1.000 .000,00$, o que pode ser decorrência de todas as prefeituras ser das grandes capitais brasileiras, demandando recursos financeiros maiores.

\subsection{PERFIL DO RESPONSÁVEL PELA CONTROLADORIA OU UNIDADE CENTRAL DE CONTROLE INTERNO}

Nesta seção buscou-se identificar as principais características associadas ao perfil dos profissionais que são responsáveis pela Controladoria ou UCCls das prefeituras. Os dados envolvem caracterizações quanto à nomenclatura atribuída ao cargo do responsável pela unidade, a formação acadêmica e a existência de experiência em área relacionada com controle, anterior a exercida no cargo.

Quanto as denominações dos cargos para os responsáveis pelo controle municipal, identificou-se, neste estudo, que elas refletem as nomenclaturas que esses departamentos possuem, já que $66,6 \%$ dos responsáveis por eles são denominados controladores, $20 \%$ secretários, 6,7\% auditor, e ainda foi identificada e especificada como "Outra" o cargo "Subsecretário Municipal de Controle Interno".

Quanto à formação acadêmica dos mesmos, observou-se que diferente dos resultados de estudos semelhantes, como os de Azevedo e Leitão (2018) e Bonetti, Wernke e Zanin (2018), a maioria (53,3\%) dos profissionais responsáveis são graduados em Ciências Jurídicas/ Direito, seguidos por $40 \%$, que representam aquelas que possuem graduação em Ciências Contábeis e 6,7\% em Administração. Estes achados podem ser explicados pelas exigências da formação acadêmica destes profissionais existentes nos editais dos concursos públicos, já que na realidade investigada por Silveira, Gasparetto, Lunkes e Schnorrenberger (2018), a formação em Direito aparece em 62\% do total analisado, ficando atrás de Ciências Contábeis (75\%) e Administração (68\%).

Com relação à experiência anterior em área relacionada a controle, verificou-se que a maioria dos responsáveis $(80 \%)$ possui experiência anterior ao cargo exercido relacionado à área de controle, o que é considerado importante para a implementação e consolidação das atividades de controle na gestão municipal, segundo Azevedo e Leitão (2018).

\subsection{FUNÇÕES DESEMPENHADAS PELAS CONTROLADORIAS PÚBLICAS MUNICIPAIS}

No que concerne às funções desempenhadas pelas Controladorias Públicas Municipais, como apresentada na seção metodológica, utilizou-se as funções atribuídas às 
Controladorias Públicas, definidas por Suzart, Marcelino e Rocha (2011), que foram as funções contábil, gerencial-estratégica, tributária, proteção e controle dos ativos, controle interno (subfunções auditoria, corregedoria, ouvidoria e transparência) e controle de riscos.

Segundo resultados apresentados na Tabela 2, a função controle interno é a única executada por todas as unidades participantes do estudo, enquanto que a função gerencial estratégica é exercida por $73,3 \%$, seguida pela função proteção e controle de ativos (60\%), e controle de risco (53,3\%). As funções contábil e tributária aparecem com igual representatividade, sendo desempenhada por 6 das 15 unidades.

Tabela 2 - Funções de Controladoria Executadas

\begin{tabular}{|c|c|c|}
\hline Funções de Controladoria executadas & Frequência & $\%$ \\
\hline $\begin{array}{c}\text { Função Contábil } \\
\text { (Corresponde à gestão das atividades desenvolvidas pela contabilidade) }\end{array}$ & 6 & $40 \%$ \\
\hline $\begin{array}{l}\text { Função Gerencial-Estratégica } \\
\text { (Correspondem às atividades que visam o apoio à tomada de decisões e ao } \\
\text { alcance dos objetivos organizacionais) }\end{array}$ & 11 & $73,3 \%$ \\
\hline $\begin{array}{l}\text { Função Tributária } \\
\text { (Correspondem às atividades relativas à Contabilidade Tributária (ou fiscal), } \\
\text { com o objetivo de atender às obrigações legais, fiscais e acessórias previstas } \\
\text { em leis e em normas tributárias) }\end{array}$ & 6 & $40 \%$ \\
\hline $\begin{array}{c}\text { Função Proteção e Controle de Ativos } \\
\text { (Correspondem às atividades de salvaguarda dos ativos da organização) }\end{array}$ & 9 & $60 \%$ \\
\hline $\begin{array}{c}\text { Função Controle Interno } \\
\text { (Correspondem às atividades relacionadas ao desenvolvimento, a } \\
\text { implementação e o acompanhamento do sistema de controle interno) }\end{array}$ & 15 & $100 \%$ \\
\hline $\begin{array}{c}\text { Subfunção Auditoria } \\
\text { (Tem como finalidade avaliar os controles internos administrativos dos órgãos } \\
\text { e entidades jurisdicionados, examinar a legalidade, legitimidade e avaliar os } \\
\text { resultados da gestão municipal) }\end{array}$ & 14 & $93,3 \%$ \\
\hline $\begin{array}{c}\text { Subfunção Corregedoria } \\
\text { (Tem como finalidade apurar os indícios ilícitos praticados no âmbito da } \\
\text { administração pública, e promover a responsabilização dos envolvidos, por } \\
\text { meio da adoção de procedimentos) }\end{array}$ & 6 & $40 \%$ \\
\hline $\begin{array}{l}\text { Subfunção Ouvidoria } \\
\text { (Tem como finalidade fomentar o controle social e a participação popular, } \\
\text { através do recebimento, registro e tratamento de denúncias e manifestação do } \\
\text { cidadão sobre os serviços prestados e adequada aplicação de recursos) }\end{array}$ & 11 & $73,3 \%$ \\
\hline $\begin{array}{c}\text { Subfunção Transparência } \\
\text { (Tem como finalidade permitir à sociedade o acesso à informação, a fim de } \\
\text { colaborar no controle das ações de seus governantes, com intuito de checar se } \\
\text { os recursos públicos estão sendo usados como deveriam) }\end{array}$ & 14 & $93,3 \%$ \\
\hline $\begin{array}{c}\text { Função Controle de Risco } \\
\text { (Correspondem às atividades de identificar, mensurar, analisar, avaliar, } \\
\text { divulgar e controlar os diversos riscos envolvidos na gestão, bem como seus } \\
\text { possíveis efeitos) }\end{array}$ & 8 & $53,3 \%$ \\
\hline Outras Funções & 5 & $33,3 \%$ \\
\hline
\end{tabular}

Fonte: Dados da Pesquisa.

Azevedo e Leitão (2018) explicam que a função controle interno aparece com a maior expressividade, porque, por muitas vezes, ela é confundida como a única função a ser desenvolvida pela controladoria, sendo a mais importante e reconhecida pelos profissionais de controle. Também foram mencionadas outras funções exercidas pela controladoria "promoção da integridade", "fomento ao controle social", "defesa do usuário do serviço público" e "prevenção à corrupção". 
Estes resultados apresentam pontos em comum com a investigação das funções executadas pelas controladorias das prefeituras municipais de Azevedo e Leitão (2018) e Bonetti, Wermke e Zanin (2018). Contudo, a existência de pontos divergentes corrobora o entendimento de que a abordagem das funções da controladoria também é não consensual na esfera pública, assim como acontece na literatura.

Os achados comunicam que, devido às funções executadas no âmbito investigado, o controller, assim como na esfera privada, tem migrado de um perfil tecnicista para um perfil gerencial-estratégico, sendo assim um misto do "contador de feijão" e do "parceiro de negócios" de Weber (2011). Esta percepção também é consoante com a análise das vagas de controlador ofertadas em concursos públicos de Silveira, Gasparetto, Lunkes e Schnorrenberger (2018), que segundo os mesmos tem que obedecer ao princípio da legalidade, sendo permitido ao controller apenas executar o que é autorizado por lei.

Os expressivos resultados quanto à execução das subfunções auditoria, ouvidoria e transparência confirmam um papel importante da controladoria na administração pública, que é atuar o de atuar no combate a corrupção, o que é corroborado pelo entendimento de Catapan (2016) ao mencionar a transparência e accountability como componentes de sustentação da governança alicerçados pela controladoria.

Ainda em relação às funções executadas, observaram-se, ao analisar a quantidade de funções da controladoria executadas pelas UCCls, que apenas $13,3 \%$ realizam todas as funções investigadas. Os resultados também elucidaram que 80\%, representando 12 áreas participantes, executam de 03 a 05 funções da controladoria. Estes resultados também confirmam a ausência de uniformidade quanto à efetividade das ações exercidas pelo controle na esfera pública municipal, mas demonstram que às funções executadas pelas controladorias municipais estão alinhadas com o papel da mesma em permitir uma boa gestão dos recursos, bem como o de apoiar o controle externo na verificação dos atos da administração pública, quanto à legalidade, legitimidade, economicidade da utilização dos recursos públicos.

\section{CONSIDERAÇÕES FINAIS}

A controladoria desponta como alvo de diversos estudos frente à sua ascendência no complexo cenário em que se vivem às organizações. Devido ao seu papel informacional, a controladoria, como área do conhecimento ou setor de uma instituição, é considerada de suma importância para o alcance da longevidade e objetivos das corporações, resultado em seu prestígio no campo organizacional.

Na esfera pública, a controladoria ou unidade central de controle interno pode avaliar a exatidão e regularidade das contas públicas, e ainda mensurar a economicidade, a eficiência e a legalidade da gestão governamental. Além de acompanhar a execução das atividades orçamentária, financeira, contábil, patrimonial e operacional, o departamento de controle interno fornece suporte e orientação pertencentes à legalidade, eficiência e moralidade das práticas operacionalizadas, culminando o atendimento aos interesses da sociedade.

No entanto, na prática, nota-se que, embora existam os dispositivos legais (a Lei 4.320 de 1964; a Constituição Federal de 1988; e a Lei Complementar 101 de 2000, comumente denominada Lei de Responsabilidade Fiscal (LRF)) que tratam sobre sua obrigatoriedade nas instituições públicas, em muitas prefeituras não se desenvolvem unidades de controle interno, ou ainda que se observe que estas estão em fase de implementação. Por esta razão, o presente estudo buscou identificar as características das Controladorias das prefeituras das capitais do país, sobretudo no que se refere às funções executadas. 
Os principais achados permitem afirmar que, na realidade investigada, as unidades são denominadas Controladoria Geral do Município, formalizadas como secretarias as quais funcionam 8 horas por dia e tem dotação orçamentária acima de $\mathrm{R} \$ 1.000 .000,00$. Sobre a constituição de seu quadro de pessoal, grande parte são compostas por mais de 25 profissionais, e embora a maioria destes departamentos possua carreira específica de controle municipal, seus servidores se enquadram, com representatividade, como profissionais que não são da carreira de controle, ou são funcionários comissionados.

No que se refere às características dos responsáveis pelas controladorias municipais, identificou-se que em sua maioria já são denominados controladores, graduados em ciências jurídicas/ direto, e com experiência anterior ao cargo exercido relacionado à área de controle.

Em relação ao principal objetivo desta pesquisa, a identificação das funções desempenhadas pelas controladorias públicas municipais, percebeu-se que a função controle interno foi a única executada por todas as unidades participantes do estudo, enquanto que a função gerencial estratégica foi exercida por $73,3 \%$, seguida pela função proteção e controle de ativos (60\%), e controle de risco (53,3\%). Os dados também demonstraram que $80 \%$, representando 12 unidades participantes, executam de 03 a 05 funções da controladoria.

O estudo evidenciou a existência de não conformidade entre as funções desempenhadas pelas controladorias públicas municipais das capitais brasileiras, bem como de outros pontos divergentes quanto às suas características. Contudo, por se tratarem das capitais do Brasil, percebe-se certo estágio de avanço quanto à consolidação do setor, em comparação com resultados de estudos semelhantes anteriores.

Acredita-se que elencar quais as funções básicas da controladoria na realidade da esfera pública municipal é um exercício fundamental que pode auxiliar na orientação desta área do conhecimento ainda pouco explorada. Os resultados deste estudo podem, não apenas desencadear outras investigações, como propiciar a identificação e consolidação das funções básicas da controladoria pública, visto que no Brasil ainda não existe consensualidade, o que pode culminar em ganhos para a prática e ações diárias desta unidade organizacional.

Ao proporcionar maiores discussões sobre a controladoria pública, amplia-se o conhecimento sobre esta seara, visto que ainda é considerado um assunto pouco abordado nas pesquisas científicas brasileiras. Devido à sua importância, ao explorar a realidade pública da controladoria, pode-se contribuir positivamente para evitar fenômenos como a corrupção já que a realização de controles internos, acompanhamento da execução orçamentária e financeira, e ainda a fiscalização dos contratos administrativos e prestação de contas no setor público aparecem na literatura e na realidade investigada como algumas de suas funções básicas.

Compreende-se que o número de prefeituras participantes do estudo representa uma limitação do mesmo. Por este motivo, sugere-se que outras pesquisas com abordagens afins, e em outros municípios brasileiros, possam ser desenvolvidas para consolidar o tratamento e compreensão das funções da controladoria na esfera pública municipal. Ainda se recomenda o desenvolvimento de outras investigações em outros aspectos da controladoria e no âmbito de outras esferas do setor público.

\section{REFERÊNCIAS}

ALMEIDA, C. J. A.; TAFFAREL, M.; GERIGK, W. Gestão fiscal responsável através da Implantação de um departamento de controladoria. Revista Capital Científico, Guarapuava PR, v.1, n.1, p.27-41, jan./dez. 2003. 
ASSIS, L.; SILVA, C. L.; CATAPAN, A. As funções da controladoria e sua aplicabilidade na administração pública: Uma análise da gestão dos órgãos de controle. Revista Capital Científico, Guarapuava, v. 14, n. 3, p. 26-43, jul./set. 2016. DOI:

https://doi.org/10.5935/2177-4153.20160019.

AZEVEDO, T. K. G. N.; LEITÃO, C. R. S. Funções Das Controladorias Municipais: Um Estudo nas Prefeituras Pernambucanas. In: Congresso de Ciências Contábeis e Atuariais da UFPB, 2., 2018, João Pessoa, Paraíba. Anais... Paraíba: UFPB, 2018.

BABBIE, E. Métodos de Pesquisas de Survey. Tradução Guilherme Cezarino. Belo Horizonte: Ed. UFMG, 1999.

BENĈOVÁ, M.; KAL'AVSKÁ, A. Importance of the controllership for the company performance software company experience. Ekonomie a Management, Liberec, v. 2, p. 76-83, 2009.

BEUREN, I. M.; BOGONI, M. N.; FERNANDES, L. Análise da abordagem da controladoria em dissertações dos programas de pós-graduação em ciências contábeis. Revista Brasileira de Gestão de Negócios, São Paulo, v. 10, n. 28, jul./set. 2008.

BORINELLI, M. L. Estrutura conceitual básica de controladoria: sistematização a luz da teoria e da práxis. 2006. Tese (Doutorado em Ciências Contábeis) - Universidade de São Paulo, São Paulo, 2006.

BRASIL. [Constituição (1988)]. Constituição da República Federativa do Brasil. Brasília, DF: Senado Federal: Centro Gráfico, 1988. 292 p.

BRASIL. Lei $n^{\circ}$. 4.320, de 17 de março de 1964. Institui o Código Civil. Diário Oficial da União. Disponível em: < http://www.planalto.gov.br/ccivil_03/Leis/14320.htm>. Acesso em: 10 mai. 2018.

BRASIL. Lei Complementar no. 101, de 04 de maio de 2000. Institui o Código Civil. Diário Oficial da União. Disponível em: < http://www.planalto.gov.br/ccivil_03/leis/LCP/Lcp101.htm>. Acesso em: 10 mai. 2018.

CALIJURI, M. S. S.; SANTOS, N. M. B. F.; SANTOS, R. F. Perfil do controller no contexto organizacional atual brasileiro. In: Congresso Brasileiro de Custos, 12., Florianópolis, 2005. Anais... Florianópolis: 2005.

CARNEIRO JÚNIOR, E. S.; OLIVEIRA, J. R. S. Falhas de controle interno nas contas municipais da microrregião de Feira de Santana apontadas pelo Tribunal de Contas dos Municípios da Bahia (2005/2009). In: Congresso USP de Controladoria e Contabilidade, 12., São Paulo, 2012. Anais... São Paulo: USP, 2012.

CAVALCANTE, D. S.; PETER, M. G. A; MACHADO, M. V. Organização dos órgãos de controle interno municipal no estado do Ceará: um estudo na região metropolitana de Fortaleza. Advances in Scientific and Applied Accounting, São Paulo v. 4, n. 1, p. 24-43, 2011. 
CHANDLER, A. Strategy and structure: chapters in the history of the industrial enterprise. Cambridge, MA: MIT Press, 1962.

CHIARELLI, L.; CHEROBIM, A. P. M. Características de sistema de controle interno municipal para atuação reguladora e orientadora da gestão pública. Revista Interdisciplinar Científica Aplicada, Blumenau, v.3, n.1, p.24-42, Sem I. 2009.

CHARTERED GLOBAL MANAGEMENT ACCOUNTANTS. Global management accounting principles, 2014. Disponível em:

<https://www.cgma.org/content/dam/cgma/resources/reports/downloadabledocuments/gl obal-management-accounting-principles.pdf > Acesso em: 05 de jun. 2018.

CRESWELL, J. W. Projeto de pesquisa: métodos qualitativo, quantitativo e misto; tradução Magda Lopes. 3. ed. - Porto Alegre: ARTMED, 2010.

CRUZ, F.; GLOCK, J. O. Controle Interno nos Municípios: Orientação para a implementação e relacionamento com os tribunais de contas. São Paulo: Atlas, 2003.

CRUZ, M. C. M. T.; SILVA, T. A. B.; SPINELLI, M.V. O papel das controladorias locais no cumprimento da Lei de Acesso à Informação pelos municípios brasileiros. Cadernos EBAPE.BR, Rio de Janeiro v. 14, n. 3, p. 721-743, 2016. DOI: http://dx.doi.org/10.1590/1679395131556

CRUZ, M. D. C. M. T.; SPINELLI, M. V. C.; SILVA, T. A. B.; CARVALHO, M. A. T. Controle Interno em Municípios Brasileiros: uma análise das Controladorias - Gerais dos municípios diante do modelo da Controladoria - Geral da União, 2014. Revista de Gestión Pública, Santiago, v. 3, n. 2, p. 297-328, 2014.

CUNHA, T. M.; AMORIM, T. N. G. F.; SILVA, M. R. O Ensino da Disciplina de Controladoria nos Cursos de Pós-Graduação Lato Sensu em Pernambuco. In: Congresso Nacional de Administração e Contabilidade - AdCont 2018, 10, 2018. Anais... Rio de Janeiro, RJ, Brasil, 2018.

ECKERT, A.; MECCA, M. S.; STUMPF, E. C.; SOST, C. M. Análise do perfil da controladoria na gestão pública: o caso dos municípios gaúchos pertencentes ao Vale do Caí. In: Congresso Virtual Brasileiro de Administração - Convibra, 9, 2012, São Paulo. Anais... São Paulo: Convibra.

GIL, A. C. Como elaborar projetos de pesquisa. 5. ed. São Paulo: Atlas, 2010.

GONÇALVES, J. L. Planejamento estratégico e a controladoria como método de apoio ao empreendedor nas pequenas empresas. Monografia (Pós-Graduação em Gestão de Negócios) - Universidade Federal do Paraná, Curitiba, 2013.

KANITZ, S. C. Controladoria: teoria e estudos de casos. São Paulo: Pioneira, 1976. 
LUNKES, R. J.; SCHNORRENBERGER, D.; ROSA, F. S. Funções da Controladoria: uma análise no cenário brasileiro. Revista Brasileira de Gestão de Negócios, São Paulo, v. 15, n. 47, p. 283 299, 2013. DOI: http://dx.doi.org/10.7819/rbgn.v15i47.1185.

MELLER, A.; LOPES, D.; LUNKES, R. As funções da Controladoria sob a perspectiva dos estágios de desenvolvimento de Weber. In: CONGRESSO UFSC, 5, 2014, Florianópolis. Anais... Florianópolis, 2014.

MONTEIRO, J. M.; BARBOSA, J. D. Controladoria empresarial: gestão econômica para as micro e pequenas empresas. Revista da Micro e Pequena Empresa, Campo Limpo Paulista v. 5, n. 2, p. 38-59, 2011. DOI: https://doi.org/10.6034/194.

NASCIMENTO, A. M.; REGINATO, L. Controladoria: um enfoque da eficácia organizacional. São Paulo: Atlas, 2010.

OLIVEIRA, A. B. S. Controladoria governamental: governança e controle econômico na implantação das políticas públicas. São Paulo: Atlas, 2015.

OLIVEIRA, L. M.; PEREZ JÚNIOR, J. H.; SILVA, C. A. S. Controladoria Estratégica: textos e casos práticos com solução. 8a. Ed. São Paulo: Atlas, 2011.

OLIVEIRA JÚNIOR, N. J.; CHAVES JÚNIOR, O. D. L.; LIMA, M. S. A controladoria nas organizações públicas municipais: um estudo de caso. Revista Universo Contábil, Blumenau, v. 5, n. 1, p. 38-54, 2009. DOI: http://dx.doi.org/10.4270/ruc.20095.

ORO, I. M.; DITTADI, J. R.; CARPES, A. M. D. S.; BENOIT, A. D. O perfil do profissional de controladoria sob a óptica do mercado de trabalho brasileiro. Pensar Contábil, Rio de Janeiro, v. 11, n. 44, p. 5-15, 2009.

PELEIAS, I. R. Controladoria: gestão eficaz utilizando padrões. São Paulo: Saraiva, 2002.

PRESTES, C. D. F.; ASSUNÇÃO, U. Controladoria: Instrumento de gestão e tomada de decisão nas empresas. Revista de Administração e Contabilidade - RAC, Belém, v. 2, n. 4, 2015.

REBIÉN, A. R.; AMORIM, A. V. Controladoria na administração pública municipal: estudo de modelo para prefeitura de Nova Santa Rita/RS. 2008. Disponível em:

http://www.congressocfc.org.br/hotsite/trabalhos_1/136.pdf Acesso em: 22/12/2018.

RODRIGUES, S. A.; BETIM, L. A.M. Controladoria em uma entidade pública: um estudo de caso na cidade de Ponta Grossa. Revista Organização Sistêmica, Curitiba, v. 5, n. 3, p. 110 127, 2014.

ROZA, M. M. C.; ALBERTON, L.; LUNKES, R. G. Perfil da Controladoria em Prefeituras localizadas nas cidades de grande porte do Estado do Rio Grande do Sul. In: Congresso UFSC de controladoria e finanças, 3., 2009, Florianópolis, 2009. Anais...Florianópolis: UFSC, 2009. 
SCHMIDT, P.; SANTOS, J. L. A Controladoria e a análise discriminante do consumidor do ecommerce. Revista Internacional de Economia y Gestion de las Organizaciones, Madrid, v. 3, p. 1-15, 2014.

SILVA, A. C. R. Metodologia da pesquisa aplicada à contabilidade. UFBA, Faculdade de Ciências Contábeis, 2017.

SILVA, N. R.; CARNEIRO, A. F.; RAMOS, E. G. Controladoria no setor público: uma comparação entre as leis de criação em quatro dos maiores municípios de Rondônia e a literatura.

Revista Evidenciação Contábil \& Finanças, João Pessoa, v. 3, n. 2, p. 73-87, ago. 2015. DOI: 10.18405/recfin20150205.

SILVEIRA, M.; GASPARETTO, V.; LUNKES, R. J.; SCHNORRENBEGER, D. Análise das vagas de controlador ofertadas em concursos públicos. Revista Contabilidade e Controladoria, v. 10, n. 2, p. 123-139, mai./ago. 2018. DOI: http://dx.doi.org/10.5380/rcc.v10i2.51870.

SIQUEIRA J. R.; SOLTELINHO, W. O profissional de controladoria no mercado brasileiro: do surgimento da profissão aos dias atuais. Revista Contabilidade \& Finanças, São Paulo, v. 12, n. 27, p. 66-77, 2001.

SOARES, L. L. Características do sistema de controle interno municipal: um estudo na Prefeitura de Municipal de Ouro Preto. Dissertação (mestrado) - Universidade FUMEC. Faculdade de Ciências Empresariais, 2012.

SOUZA, C. T. D. A evolução da Controladoria: Um estudo no Brasil. Dissertação (Mestrado em Ciências Econômicas) - Faculdade de Ciências Econômicas da Universidade Federal do Rio Grande do Sul (UFRGS), Porto Alegre, 2015.

SOUZA, M. A. DURIGON, A. R. Controladoria em instituição pública de ensino superior: percepção do seu papel sob a ótica dos gestores da Unemat. In: CONGRESSO BRASILEIRO DE CUSTOS-ABC. Anais... 2012.

SUZART, J. A. S., MARCELINO, C. V., ROCHA, J. S. As instituições brasileiras de Controladoria pública - teoria versus prática. Journal of Accounting, Management and Governance, Brasília, v. 14, n. 1, p. 44-56, jan./abr. 2011.

VASCONCELOS, G.; LIMA, A. C. Análise Bibliométrica da Produção Científica acerca da Controladoria. Management Control Review, Recife, v. 2, n. 1, p. 31-49, 2017.

VASCONCELOS, M. T. C.; SAMPAIO, F. J. C de S.; SILVA NETO, A. F.; DUQUE, S. Funcionalidade do controle interno nos municípios: um estudo nas prefeituras de uma região metropolitana do nordeste brasileiro. Advances in Scientific and Applied Accounting, São Paulo, v. 5, n. 2, p. 201-221, 2012.

WEBER, J. The development of controller tasks: explaining the nature of controllership and its changes. Journal of Management Control, Dresden, v. 22, n.1, p. 25-46, 2011. DOI: https://doi.org/10.1007/s00187-011-0123-x 